\title{
Study on Optimization of Automobile Crash Box Considering the Influence of Strain Rate
}

\author{
Chih-Keng Chen ${ }^{1}$, Yu-Jie Ma ${ }^{1,2, *}$ \\ ${ }^{1}$ Department of Vehicle Engineering, National Taipei University of Technology, Taipei, China \\ ${ }^{2}$ School of Physics and Electromechanical Engineering, Longyan University, Longyan, China
}

Email address:

Mayujie_fzu@163.com (Yu-Jie Ma)

${ }^{*}$ Corresponding author

\section{To cite this article:}

Chih-Keng Chen, Yu-Jie Ma. Study on Optimization of Automobile Crash Box Considering the Influence of Strain Rate. International Journal of Mechanical Engineering and Applications. Vol. 8, No. 2, 2020, pp. 75-80. doi: 10.11648/j.ijmea.20200802.13

Received: April 20, 2020; Accepted: May 28 2020; Published: June 8, 2020

\begin{abstract}
The strain rate is one of the main factors that determines the yield strength of the material, which has a great influence on the accuracy of the numerical simulation of the automobile crash box. The numerical simulation of the crash box considering the strain rate of the material is carried out, and found that the impact force on the longitudinal beam of the car body is large and the energy absorption ability is small during the collision process. Through two sets of optimization studies, the results show that increasing the double-sided convex groove at the proper position of the front crash box can effectively reduce the impact force transmitted to the car body at the initial stage of the collision, and at the same time reduce the energy absorption ability of the crash box; Adding double-sided grooves at the front crash box can make the crash box collapse smoothly, cut down the collision force transmitted to the car body, and increase the energy-absorbing ability. At the same time, the results of the two optimization designs are verified by the methods: the sense of crushing deformation and the average square of all nodes velocity.
\end{abstract}

Keywords: Crash Box, Strain Rate, Numerical Simulation

\section{Introduction}

With the rapid development of Chinese industry, China's automobile industry has made unprecedented achievements. According to statistics, at the end of 2019, there were 260 million cars in China [1]. Automobile has become an indispensable means of transportation in people's life and work. The total number of cars increased while traffic accidents also showed an upward trend. According to relevant statistics, $67 \%$ of the direct impact occurred in vehicle accidents [2-5], which is the most dangerous to the life safety of drivers and passengers. The crash box installed between the bumper beam and the frame longitudinal beam is an important energy-absorbing component when the car is impacted. On the one hand, it can absorb the energy from the beam, reduce the damage of the front parts of the body and protect the safety of passengers, on the other hand, it can transfer the impact force to the longitudinal beam and disperse it [6-8].
Therefore, the study of the automobile crash box and its performance optimization are of great significance to improve the passive safety of the vehicle and to protect the safety of drivers and passengers.

Many researches have been carried out on the research and optimization of the crash box: Zhang optimized the structure of the crash box under low speed collision, built the multi-cell crash box structure, and improved the crash box unit mass energy absorption [9].

Wang based on the biomimetic design of human tibia, established a rigid wall-absorption box frontal collision model, and carried out the optimal design of the crash box by using a miniature genetic algorithm based on archiving and an improved non-dominated sorting genetic algorithm, which reduced the quality of the crash box and improved the energy absorption ratio [10].

Marzbanra used aluminum alloy extruded under elastic boundary conditions to make crash boxes. The experimental results showed that the aluminum alloy material made of elastic boundary can change the 
deformation mode of the crash box thus reducing the maximum impact force [11].

BELINGARDI studied the response of the metal bumper beam under low speed impact and discussed the influence of the reinforcement bars and the thickness of the crash box on its performance [12].

Most of these studies focus on the optimization design of the crash box for low speed collision, and less research on the influence of strain rate on the yield strength of the material during collision. In this paper, the crash box was simulated by numerical simulation considering the strain rate of material and found that the average value of the peak stress of the crash box transmitted to the longitudinal beam during the collision is larger and the average value of the acceleration at the node of the crash box is larger. In order to solve these problems, the optimal design of the crash box is studied.

\section{Numerical Simulation of the Crash Box}

The strain rate is one of the main factors that determines the yield strength of the material. When the crash box was crushed by impact force, it begins to buckle and deform. The front part is larger than the middle and back part deformation rate. In order to improve the accuracy of the numerical simulation of the crash box, the strain rate of the material is considered.

\subsection{Effect of Strain Rate on Material Properties}

As shown in Figure 1, the stress-strain diagram of the material B400 used in the crash box. The yield strength increased by 15.8 percentage points from $960 \mathrm{MPa}$ at the strain rate of $0.01 / \mathrm{s}$ to $1112 \mathrm{MPa}$ at the strain rate of $1000 / \mathrm{s}$. It can be seen from the diagram that the yield strength of the material has a great relationship with the strain rate, and the larger the strain rate, the higher the stress-strain curve of the corresponding material, that is, the greater the yield strength of the material.

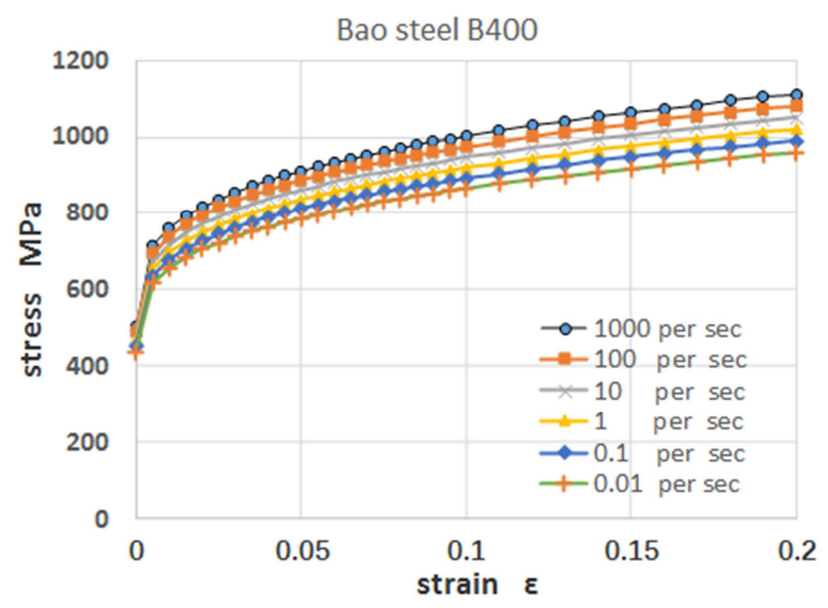

Figure 1. B400 Stress-Strain Curve under Different Strain Rate.

\subsection{Numerical Simulation of Crash Box}

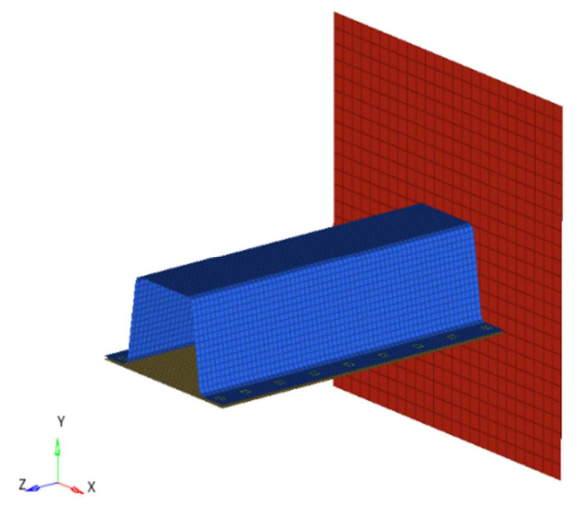

Figure 2. Numerical simulation of the crash box.

In 3D drawing software, a geometric model of crash box in a car bumper system with an isosceles trapezoid cross section is established. The main dimension parameters are: thickness $1.5 \mathrm{~mm}$, upper bottom $60 \mathrm{~mm}$, lower $80 \mathrm{~mm}$, high $60 \mathrm{~mm}$ and length $250 \mathrm{~mm}$. By introducing the finite element analysis software, we can extract the center surface of the 3D model and divide the grid, then assign the material property to the structure and constraint the modeling. To simplify the simulation, as shown in figure 2, the part of the rear end of the crash box connected with the longitudinal beam of the car body is fixed in this model, and the degree of freedom of the part node is constrained in 6 directions. The rigid wall impacts the crash box at a constant speed of $36 \mathrm{~km} / \mathrm{h}$, with an impact time of $0.014 \mathrm{~s}$ [13]. The properties of the material take into account the effect of strain rate on yield strength, whose value is the same as the stress-strain value shown in figure 1, and then the numerical simulation of the crash box considering the strain rate of the material is carried out.

\subsection{Results and Analysis}

A good crash box can effectively reduce the impact force transmitted to the body and has a large energy absorption capacity. The impact force transmitted to the body during the collision process can be evaluated by the average stress of the unit at the back end of the crash box connecting the longitudinal beam and the energy absorption ability can be evaluated from the mean acceleration of all nodes that compose the crash box. As shown in Figure 3, the stress of each element at the end of the crash box connecting the longitudinal beam at different times. When the rigid wall was in full contact with the front part of the crash box at $0.001 \mathrm{~s}$, the crash box was caused elastic-plastic deformation and the stress mean value transmitted to the back end connecting the longitudinal beam appears the first peak, rises from 0 to 248.6 $\mathrm{MPa}$. The second peak of impact force is produced when the crash box is basically crushed at the end of $0.014 \mathrm{~s}$ collision, and the stress mean is as high as $351.7 \mathrm{MPa}$. For the whole collision process, the mean stress of all elements transmitted to the back end is $250.7 \mathrm{MPa}$., which indicates that the impact force of the whole collision process the longitudinal beam to the car body is larger, especially the 
final impact force. From the acceleration diagram of all nodes in the crash box, it can be seen that the mean value of all node acceleration in the whole collision process is $6.25 \times 10^{7} \mathrm{~mm} / \mathrm{s}^{2}$, the impact acceleration is too large, and the energy absorption performance is poor during the collision process. In order to improve the performance of the crash box, the impact force on the car body should be reduced, and the mean acceleration of all nodes in the collision process should be reduced. Therefore, it is necessary to optimize the design of the crash box.

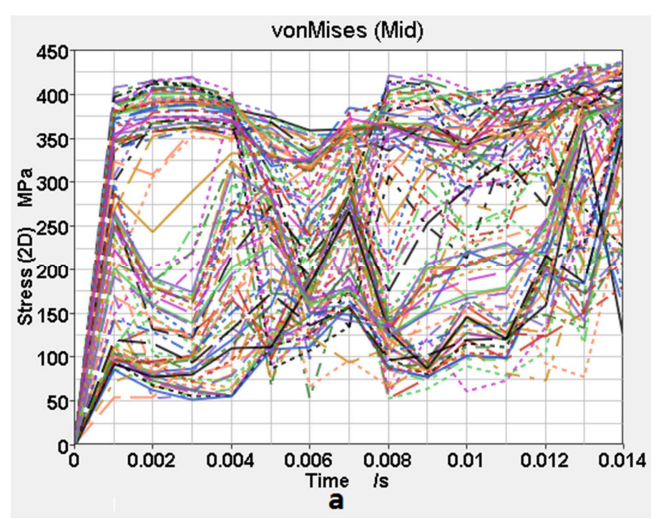

(a) The relationship between stress and time of all elements connected to the longitudinal beam

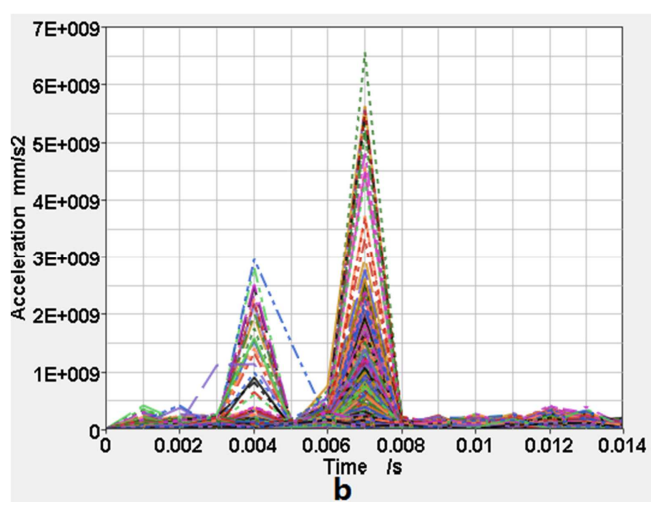

(b) The relationship between acceleration and time of all nodes in the crash box

Figure 3. Relationship between element stress, nodes acceleration and time.

\section{Optimize the Design of the Crash Box}

The induced slot is a concave and convex groove formed by the stamping process in a certain part of the structure, which causes the stress concentration in the position. For thin-wall components of the crash box, an additional induced slot is used to guide the collapse and deformation of the crash box, so as to effectively reduce the impact force transmitted to the vehicle body and improve its energy absorption capacity. Combined with the characteristics of the collision process of the crash box, the two groups of optimizations are designed as shown in Figure 4.

\subsection{Optimization Designs}

As shown in Figure 4, by analyzing the crushing deformation of the original crash box, the optimal design A increases double-sided convex groove at the two isosceles of the trapezoid to induce the deformation of the outer bulge fold at the initial stage of the crash box collision, and reduces the peak impact force transmitted to the car body; and the optimal design $\mathrm{B}$ increases the groove at the upper double edge of the crash box, reduced the strength on the edge, and induced the inner deformation at the edge of the crash box in the initial stage of collision, so as to increase the outward fold deformation at the two waist of the crash box and reduce the peak impact force transmitted to the car body.

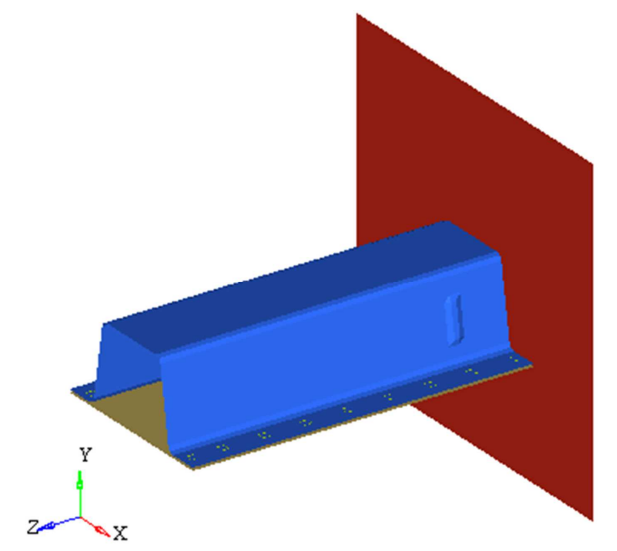

(a) double-sided convex groove

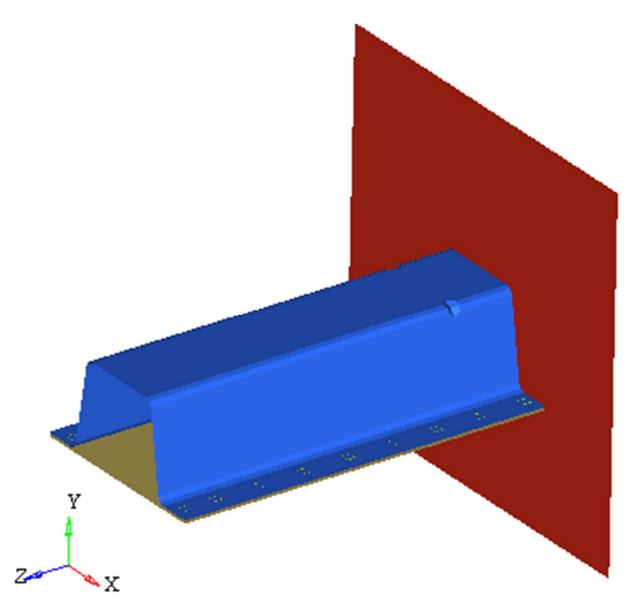

(b) double edge groove

Figure 4. Two groups of optimization design.

\subsection{The Results of Two Optimizations}

When the crash box is subjected to collision compression deformation, the mean value of stress transmitted to the back end of the crash box is positively correlated with the impact force transmitted to the car body and the mean acceleration of all the nodes of the crash box is negatively correlated with the energy absorption performance of the crash box. In the process of collision, the smaller the stress mean of the unit connected to the car body at the back end of the crash box, the smaller the impact force transmitted to the car body, the better the buffer performance of the crash box; on the contrary, the greater the impact force transmitted to the car 
body, the worse the buffer performance. In this model, the rigid wall impinges on the crash box with constant velocity and same impact time, and the work done on the crash box is certain. After collision, the smaller the mean value of acceleration of all nodes in the crash box is, the better the energy absorption ability is. On the other hand, the higher the mean acceleration of all the nodes of the crash box, the worse the energy absorption performance of the crash box.

As shown in Figure 5 and Table 1, the two optimization designs can effectively reduce the impact force transmitted to the car body during collision. The optimal design A, as for the induced slot is arranged on the symmetrical surface of the front part of the crash box, which reduces the rigidity of the two sides, makes the crash box more prone to fold deformation during the collision, plays a better buffer performance, and significantly reduces the average stress value transmitted to the car body at the beginning of the collision. At the end of the collision, due to the fold buffer decreases, the average stress of the unit at the back end of the crash box increases rapidly, and the whole process the average stress decreases $32.4 \%$ compared with the original design. During the collision, due to the decrease of rigidity, the energy absorption performance of the energy-absorbing box decreased and the average acceleration increased by $3.3 \times 10^{6} \mathrm{~mm} / \mathrm{s}^{2}$, that is $5.3 \%$ lower than that of the original design.

The optimal design B, because of induced slot is arranged on the symmetrical double edges at the front end of the crash box, which has a smaller effect on the overall rigidity of the crash box than the optimal design $\mathrm{A}$, and the fold deformation can be induced at the same time. At the beginning of the collision, the mean value of the stress transmitted to the car body was reduced compared with the original design. In the whole collision process the crash box collapsed smoothly from the front end to the back end, and the mean value of the stress transmitted to the car body was $202 \mathrm{MPa}$, which was $19.4 \%$ lower than the original design. The crash box has good induced deformation and maintains its original stiffness, for this reason, the crash box has good energy absorption performance, and its average acceleration is $13.8 \%$ lower than the original design.

Table 1. Mean of Stress and Mean of Acceleration in Collision Process.

\begin{tabular}{lll}
\hline Name & Original design & Optimal design A \\
\hline Mean Stress in Initial Collision $(\mathrm{MPa})$ & 248.6 & 136.6 \\
Mean Stress at the End of Collision $(\mathrm{MPa})$ & 351.7 & 353.0 \\
Mean stress throughout the process $(\mathrm{MPa})$ & 250.7 & 169.4 \\
Average acceleration $\left(\mathrm{mm} / \mathrm{s}^{2}\right)$ & $6.25 \times 10^{7}$ & $6.58 \times 10^{7}$ \\
increased rate of the average acceleration & 0 & $5.3 \%$ \\
\hline
\end{tabular}

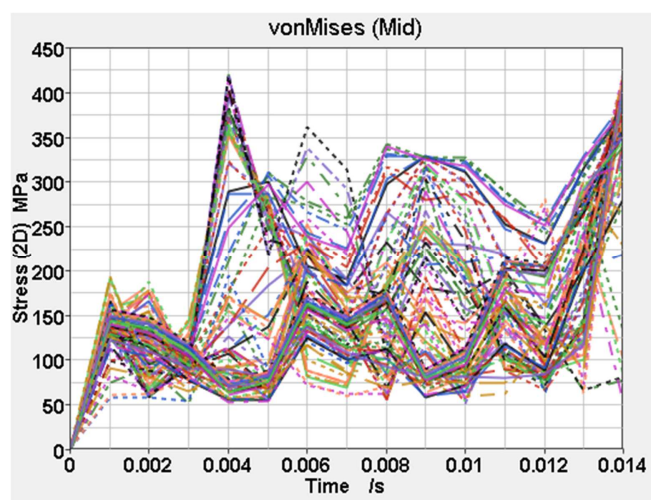

(a) Stress and time relation of all units at connecting the longitudinal beam in optimal design A

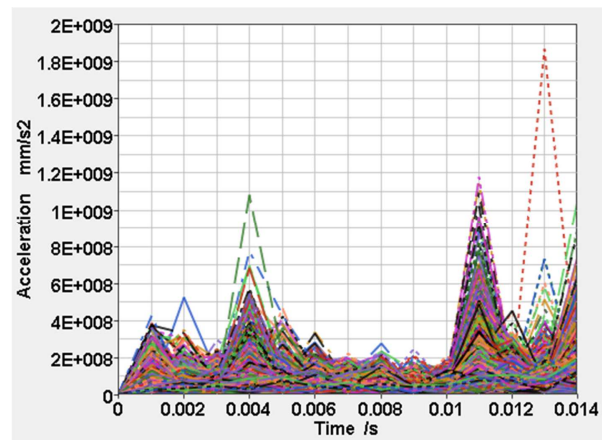

(b) Acceleration and time relationship of all nodes in the crash box in optimal design $\mathrm{A}$

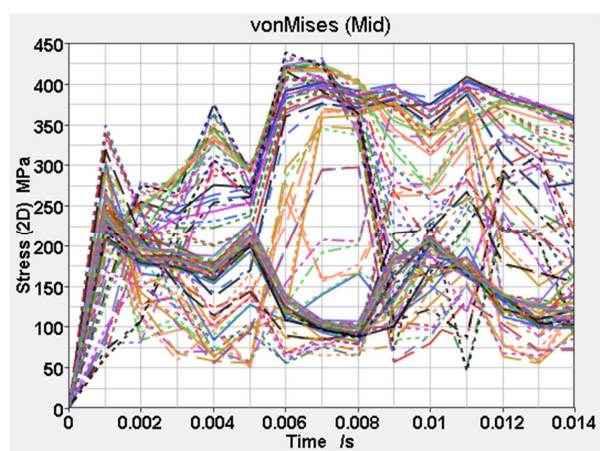

(c) Optimal design B: Stress and time relation of all units at connecting the longitudinal beam

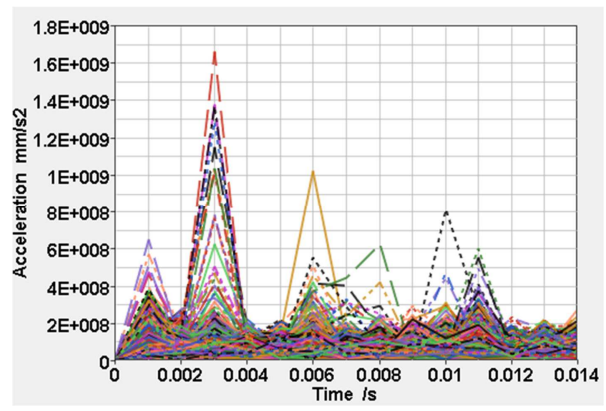

(d) Optimal design B: Acceleration and time relationship of all nodes in the crash box

Figure 5. Relationship between unit stress and node acceleration with time during post-optimized collision. 
From the results in table 1 and figure 5 , it can be concluded that: The first is that adding double-sided convex groove at the front end of the crash box can effectively reduce the impact force transmitted to the car body, at the same time reduces the energy absorption capacity of the energy absorption box; The second is to increase the double-sided groove at the front end of the crash box can make the box smooth crushing, decrease the impact force transmitted to the car body, increase the energy-absorbing ability.

\section{Validation of Optimization Design}

In this model, the crash box is fixed at one end, and the rigid wall impinges the other end of the crash box at a constant speed of $36 \mathrm{~km} / \mathrm{h}$ at the same impact time. After collision, the crash box crush deformation layer sense, the average square of all nodes velocity to some extent reflect the crash box performance. The better the fold level of the crash box after collision, the better buffer effect of the crash box is, and the more beneficial to reduce the impact force on the car body. The larger the average square of all nodes velocity, the worse the energy absorption performance of the crash box itself; On the contrary, the smaller the average square of all nodes velocity, the better the energy absorption performance of the crash box.

After verifying the above three groups of designs, the results are shown in Figure 6 and Table 2. For the original design, large plastic deformation occurred in the front and rear of the crash box at the initial stage of collision, and in the middle and late stage, the front and rear ends of the crash box were crushed and folded, accompanied by the whole bending deformation, the compression level sense was general, and the average square of all nodes velocity of the whole collision process was $4.02 \times 10^{7} \mathrm{~mm}^{2} / \mathrm{s}^{2}$.

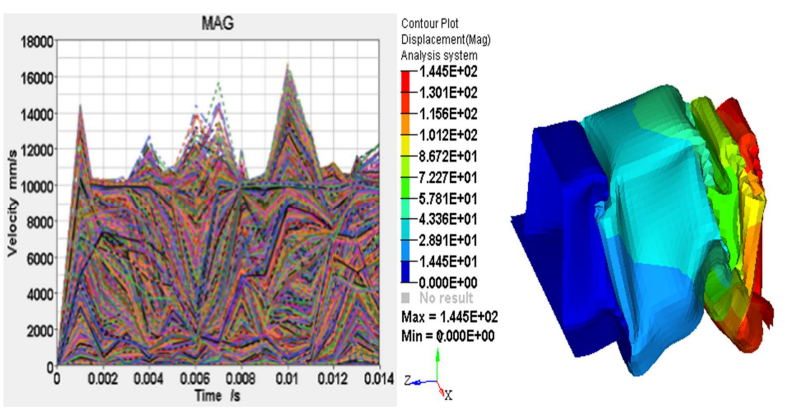

(a) the original design

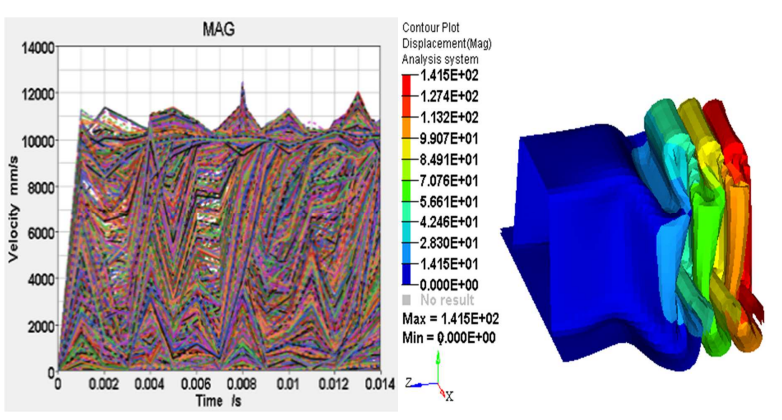

(b) optimal design $\mathrm{A}$

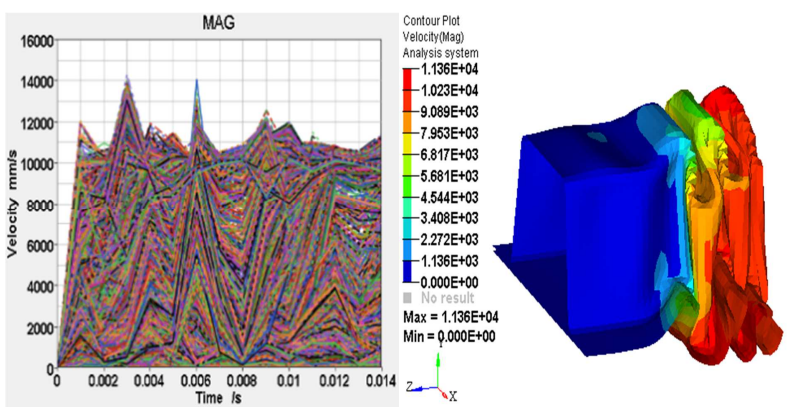

(c) optimal design $\mathrm{B}$

Figure 6. The relationship between the velocity and time of each node and distribution of velocity cloud map at the end of collision in each design.

Table 2. Average square of velocity and compression of each design collision 。

\begin{tabular}{llll}
\hline Name & Average square of velocity $\left(\mathbf{m}^{2} / \mathbf{s}^{2}\right)$ & Increased rate & Crush deformation layer sense \\
\hline Original design & $4.02 \times 10^{7}$ & 0 & general \\
Optimal design A & $4.17 \times 10^{7}$ & $3.7 \%$ & good \\
Optimal design B & $3.65 \times 10^{7}$ & $-9.2 \%$ & better \\
\hline
\end{tabular}

The optimal design A, due to the induced slot is arranged on the symmetrical surface of the front part of the crash box, which reduces the rigidity of the two sides, makes the crash box more prone to fold deformation during the collision. In the whole collision process, the crash box crushes the folds in an orderly manner from the front end to the back end, and has a good deformation layer sense. The average square of all node velocity is $4.17 \times 10^{7} \mathrm{~mm}^{2} / \mathrm{s}^{2}$, which is $1.5 \times 10^{6} \mathrm{~mm}^{2} / \mathrm{s}^{2}$ higher than the original mean of velocity. In short, the optimal design A reduce the impact force effectively, which is consistent with the conclusion that the average stress of the unit at the back end of the crash box reflects the significant decrease of impact force. The energy absorption capacity was slightly lower than that of the original scheme by $3.7 \%$, which was consistent with the conclusion that the average acceleration reflected the decrease of energy absorption capacity by $5.3 \%$.

The optimal design $\mathrm{B}$, thanks to the induced slot is arranged on the symmetrical double edge of the front end of the crash box, the design has both the overall stiffness of the original design and well induces deformed in the optimization design A. During the whole process, the crash box has a good deformation layer sense, and the average square of all node velocity is $3.65 \times 10^{7} \mathrm{~mm}^{2} / \mathrm{s}^{2}$, decreased by $9.2 \%$ compared with the original design. The above results show that this design not only reduces the impact force transmitted to the car body but also increases its energy absorption ability. It is consistent with the conclusion that the 
mean value of the unit stress connected to the car body transmitted to the car body is $19.4 \%$ lower than the original design and the average acceleration of all node is lower than the original design and the energy absorption performance is improved by $13.8 \%$.

\section{Conclusion}

(1) Increasing the double-sided convex groove in the proper position of the front end of the crash box can effectively reduce the impact force transmitted to the car body, especially to reduce the impact force transmitted to the car body at the initial stage of the collision. At the same time, it reduces the energy absorption ability of the crash box, which is reduced by $4 \%$;

(2) In the proper position at the front end of the absorption box, the double edge groove can be added to make the absorption box collapse smoothly, decrease the impact force transmitted to the car body, increase the energy absorption ability.

\section{References}

[1] National Bureau of Statistics, Statistical Bulletin of National Economic and Social Development of the People's Republic of China 2019.

<http://www.stats.gov.cn/tjsj/zxfb/202002/t20200228_172891 3.html>.

[2] Zhao Chen, Fang Teng Yuan, Zhao Jun Wei, et al. "Study on simulation analysis of vehicle rear end accidents based on accident reverse reproduction," Journal of Safety Science and Technology, Beijing, vol. 16 (2020), pp 157-163.

[3] Liu Zhong Hua, LI Xue Song, QU Tian Lei. "Multi-Objective Optimization Design of Inducing Grooves for Crash-Box," Journal of Chongqing University of Technology (Natural Science), Chongqing, vol. 10 (2017), pp 35-42, 55.
[4] Zhang Shi-bo, Liu Lan, "Projection Kinematics of Pedestrian Impacted by Minivans," China Journal of Highway and Transport, Xi'an, vol. 31 (2018), pp 262-269.

[5] Chen Kai Xian, Zeng Jun Wei, Qian Yong Sheng, et al. "Study on the Characteristics of Regional Traffic Flow Rate Control in Expressway Traffic Accidents," Highway Engineering, Changsha, vol. 43 (2018), pp 91-95.

[6] Xie Yun, Tang Zhe Hao, Wang Hang Yan, et al. "Research on lightweight bumper based on crashworthiness," Journal of Plasticity Engineering, Beijing, vol. 27 (2020), pp 81-87.

[7] Liu Wen Qi, Lian Jun He, Sebastian Münstermann, et al. "Prediction of crack formation in the progressive folding of square tubes during dynamic axial crushing," International Journal of Mechanical Sciences, London, vol. 176 (2020), pp 176.

[8] N. Nasir Hussain, Srinivasa Prakash Regalla, Yendluri V. Daseswara Rao. "Economical method for manufacturing of advanced light weight material crash box for automobiles," Materials Today, Proceedings, 2020.

[9] Zhang Yi. "Structural optimization design of automobile crash box under low-speed collision," Dalian, Dalian University of Technology.

[10] Wang C Y, Li Y, Zhao W Z, et al. "Structure design and multi-objective optimization of a novel crash box based on biomimetic structure," International Journal of Mechanical Sciences, London, vol. 138-139 (2018), pp 489-501.

[11] MARZBANRAD J, KESHAVARZI A. "A Numerical and experimental study on the crash behavior of the extruded aluminum crash box with elastic support," Latin American Journal of Solids and Structures, Brasilia, vol. 11 (2014), pp 1329-1348.

[12] BELINGARDI G, BEYENE A T, KORICHO E G, et al. "Alternative lightweight materials and component manufacturing technologies for vehicle frontal bumper beam," Composite Structures, London, vol. 120 (2015), pp 120

[13] Liu Zhen Yao, Guo Bin, Wang Lin Pin. "Numerical simulation of vehicle crashes based on LS-DYNA". Chinese Quarterly of Mechanics, Shanghai, vol. 41 (2020), pp 179-186. 